Int. J. Electrochem. Sci., 14 (2019) $1516-1528$

International Journal of

ELECTROCHEMICAL

SCIENCE

WWW.electrochemsci.org

\title{
Determination of Corrosion Types from Electrochemical Noise by Gradient Boosting Decision Tree Method
}

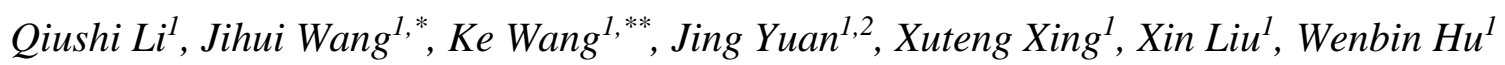 \\ ${ }^{1}$ State Key Laboratory of Hydraulic Engineering Simulation and Safety, Tianjin University, Tianjin \\ 300350, P R China \\ ${ }^{2}$ College of Physics Electronic Information Engineering, Qinghai University for Nationalities, Xining, \\ Qinghai 810007, China \\ *E-mail: qsli@tju.edu.cn (Qiushi Li), jhwang@tju.edu.cn (Jihui Wang), kewang@tju.edu.cn (Ke \\ Wang)
}

doi: $10.20964 / 2019.02 .72$

Received: 12 October 2018 / Accepted: 5 December 2018 / Published: 5 January 2019

\begin{abstract}
The corrosion behavior of X65 steel and 304 stainless steel (SS) was investigated in typical passivation, uniform corrosion and pitting solution systems by electrochemical noise (EN) technique. Eleven characteristic parameters were extracted from EN data based on statistical analysis, shot noise theory, and wavelet analysis methods. Subsequently, the data samples composed by the extracted parameters were analyzed by gradient boosting decision tree (GBDT) model. The results indicated that the proposed GBDT model could efficiently and accurately discriminate the corrosion type for data samples containing X65 steel and 304SS. The discrimination results of GBDT for the corrosion type are consistent with their corroded morphology analysis. Among the eleven parameters extracted from EN measurements, noise resistance $R_{\mathrm{n}}$, average frequency $f_{\mathrm{n}}$ and wavelet dimension of EPN (WD_E) have the greatest influence on GBDT model.
\end{abstract}

Keywords: Electrochemical noise, Gradient boosting decision tree, Corrosion type, Machine learning

\section{FULL TEXT}

(C) 2019 The Authors. Published by ESG (www.electrochemsci.org). This article is an open access article distributed under the terms and conditions of the Creative Commons Attribution license (http://creativecommons.org/licenses/by/4.0/). 